\title{
Prevention of beta cell death in chronic pancreatitis
}

\author{
Huansheng Dong, Katherine A. Morgan, David B. Adams, Hongjun Wang* \\ Department of Surgery, Medical University of South Carolina, Charleston, USA \\ Email: wangho@musc.edu
}

Received 29 August 2012; revised 30 September 2012; accepted 6 October 2012

\begin{abstract}
Chronic pancreatitis is best described as a relentless, continuous inflammatory destruction of the pancreas parenchyma, characterized by irreversible destruction of the exocrine tissues, fibrosis, and at the late stage, the destruction of endocrine cells. Current therapies for chronic pancreatitis patients focus on pain relief by medical and minimally invasive endoscopic treatment as well as surgical management with resection of diseased parenchyma and drainage of obstructed ducts. Radical treatment of chronic pancreatitis has been successful with total pancreatictomy and islet autotransplantation (TP-IAT) that may prevent maladaptive intractable pain pathways and also avoid pancreatogenic diabetes in the wellselected patient. Distinct loss of pancreatic islet cells occurs in about $30 \%-50 \%$ of patients during the progression of chronic pancreatitis when severe fibrosis develops at the late stage of the disease. Profound $\beta$ cell apoptosis induced by stresses encountered during islet isolation and transplantation further compromises $\beta$ cell survival and function after TP-IAT. The molecular mechanisms that lead to $\beta$ cell dysfunction in chronic pancreatitis remain largely undelineated. In this review, we summarize factors that may contribute to $\beta$ cell apoptosis during the disease progress and after TP-IAT and discuss potential interventional approaches that may prevent islet cell death during these processes. Such information is critical to the development of therapeutic protocols that can preserve the viability and function of $\beta$ cell in patients with chronic pancreatitis.
\end{abstract}

Keywords: Chronic Pancreatitis; Islet

Autotransplantation; Beta Cell Apoptosis; Protective Gene

\section{INTRODUCTION}

Chronic pancreatitis (CP) is characterized by longstanding inflammation of the pancreas that is notable for

${ }^{*}$ Corresponding author. the development of progressive pain, fibrosis and loss of exocrine and endocrine function [1]. Approximately 15,000 Americans are diagnosed with chronic pancreatictis each year. The pathophysiology of chronic pancreatictis is dominated by acinar cell death and loss of exocrine function of the pancreas. Endocrine insufficiency that occurs much later in the disease can lead to type 3c diabetes [2,3]. Current therapies for chronic pancreatitis patients focus on pain relief by medications and a variety of minimally invasive endoscopic procedures as well as surgical treatment with resection of diseased parenchyma and drainage of obstructed ducts $[3,4]$. Radical treatment of chronic pancreatitis has been successful with total pancreatectomy and islet autotransplantation (TP-IAT) that may prevent maladaptive intractable pain pathways and also avoid pancreatogenic diabetes in the well-selected patient [5].

Although the pathogenesis and biological behavior of chronic pancreatitis has been widely studied, mechanisms of apoptosis and proliferation of endocrine (e.g., acinar) and endocrine (e.g., insulin-secreting $\beta$ ) cells under the conditions of chronic pancreatitis remain poorly defined. Profound apoptosis of acinar cells are observed in chronic pancreatitis patients, while $\beta$ cells have been found less vulnerable than acinar cells at the early stage of chronic pancreatitis [6,7]. Nevertheless, $\beta$ cell apoptosis over a prolonged period of inflammation that influences insulin secretion develops late in the disease process. Diabetes occurs in around $30 \%-50 \%$ of patients diagnosed with long-term chronic pancreatitis [8]. In advanced stages of chronic pancreatitis, reduction of islet cells corresponds with severe $\beta$ cell dysfunction due to prolonged exposure to inflammatory cytokines, oxidative stresses and gene dysfunction [7,9]. Moreover, non-immune related stresses encountered during islet isolation and transplantation also results in a significant number of islets undergoing apoptosis after TP-IAT, which further comprise the function of $\beta$ cells [10].

In this review, we summarize molecular mechanisms that lead to $\beta$ cell dysfunction during the progress of chronic pancreatitis and after TP-IAT and discuss interventional therapies that might improve the viability and function of $\beta$ cells. Understanding such mechanisms will 
not only lead us to a better understanding of the pathogenetic mechanisms leading to $\beta$ cell death in chronic pancreatitis, but also help develop efficient therapeutic treatment protocols for this disease.

\section{MECHANISMS OF $\beta$ CELL DEATH DURING THE PROGRESS OF CHRONIC PANCREATITIS}

Long-term inflammation in patients with chronic pancreatitis impairs $\beta$ cell function and as many as 30\% $50 \%$ of patients develop a type of diabetes that differs from type 1 and type 2 diabetes [8]. The diabetes associated with chronic pancreatitis has been labeled as "type 3c" diabetes [11]. Type 3c diabetes is caused by the apoptosis of $\beta$ cells and is generally not diagnosed in the early stages of chronic pancreatitis, but manifests itself in a later stages of the disease irrespective of the etiology of chronic pancreatitis [12].

At the early stage of chronic pancreatitis, the damage to the pancreas is highly specific for the exocrine compartment and affects the endocrine islets to a less extent [13]. For example, Fas (CD95)/Fas ligand (CD95L)mediated islet cell destruction by CD95L expressing cytotoxic $\mathrm{T}$ cells is an important mechanism in the development of type 1 diabetes, but does not occur at the same extent in chronic pancreatitis patient. Exocrine cells express CD95, and shed their death by binding to the death ligands (CD95L) on infiltration $\mathrm{T}$ lymphocytes in the presence of IFN- $\gamma$, while islet cells secured themselves by expressing CD95L instead of CD95. Thus, T cells infiltrates are prevalent within acinar cells but rare within islets in pancreas with chronic pancreatitis [13-15]. Moreover, a strong induction of TNF-related apoptosisinducing ligand (TRAIL) receptor 1 and 2 (TRAIL-R1 and R2) is observed in exocrine cells, while islet cells only express TRAIL-R4 [15]. TRAIL released locally by activated pancreatic stellate cells binds to TRAIL-R1 and R2 specifically, but not TRAIL-4R, and selectively lead to exocrine apoptosis [16]. In addition, islet cells have been shown to retain their "immune-privileged" status by activated anti-apoptotic programs through NF-кB [1719].

As the disease progresses, chronic inflammation can lead to $\beta$ cell apoptosis and dysfunction. Chronic inflammation causes increasing stress and cytokine secretion by both macrophages and $\mathrm{T}$ lymphocytes with marked fibrosis that eventually leads to $\beta$ cell apoptosis and clinical diabetes [20]. The changes in the internal milieu of pancreatic tissue in chronic pancreatitis arising from the chronic inflammation and cytokine release (e.g., IFN- $\gamma$, TNF- $\alpha$ ) that leads to deranged cellular crosstalk and signaling mechanisms and altered function of islet cells. Qualitative and quantitative changes in cytokine signaling pathways determine the fate of $\beta$ cell to live and proliferate or to undergo apoptosis [21]. The apoptosis of $\beta$ cell are likely caused by the cytokine expression, oxidative stress, and reduced expression of certain genes (e.g., pancreatic duodenal homeobox 1) in the pancreas [22-24]. Apoptosis of $\beta$ cells, when it occurs, has been ascribed to immune processes initiated by CD8+ T cells or CD4+ T cells dependent on Fas/FasL as well as cytokines (e.g., IFN- $\gamma$ and TNF- $\alpha$ ). Apparently, cellular and molecular events leading to $\beta$ cell apoptosis represent the adaptive response of normal islets towards the noxious environment caused by proinflammatory cytokines.

\section{DEATH OF $\beta$ CELLS AFTER TP-IAT}

TP-IAT is being increasingly investigated and used as a treatment option for pain relief, and it is also used to prevent pancreatogenic diabetes in chronic pancreatitis [25]. Among all the treatment options, TP-IAT is a safe and effective option for chronic pancreatitis patients and has the potential to eliminate pancreatic pain without total sacrifice of the endocrine function of the pancreas $[4,26,27]$. Islets transplanted into the liver via the portal vein were found to have improved functions with time [28]. However, even though TP-IAT can improve quality of life and decreased narcotic requirement, more than $60 \%$ of patients require long-term insulin treatment [4, 27,29-31]. Non-immune related stresses encountered during islet isolation and transplantation results in a large number of islets undergoing apoptosis immediately after transplantation, and as many as 50\% - 60\% of islet cell apoptosis happens at 2 - 3 days post transplantation even under optimal conditions [32,33]. The death of pancreatic islets are likely due to transplantation-associated stress which include hypoxia, nutrient deprivation, reactive oxygen species, pro-inflammatory cytokines induced during harvesting, isolation, and implantation of the islet cell mass [10,34].

\section{APPROACHES TO PROTECT $\beta$ CELL FROM APOPTOSIS IN CHRONIC PANCREATITIS PATIENT}

In order to prevent the chronic inflammation in chronic pancreatitis patient, altering the environment where islets reside may help relieve the stress and improve islet survival and function. For example, strategies such as dietary modification, oral hypoglycemics, and exogenous insulin can help alleviate the stress of $\beta$ cell, and thus preserve islet function (Figure 1) [35,36].

It has been postulated that patients with chronic pancreatitis should be considered for TP-IAT before severe islet destruction occurs. Patient islet quality and quantity determines $\beta$ cell function after transplantation. Insulin 


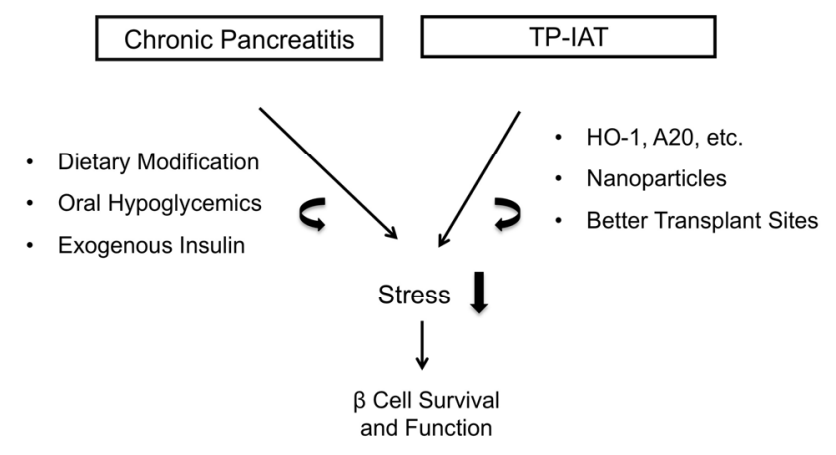

Figure 1. Approach to improve islet survival and function during chronic pancreatitis progress and during TP-IAT.

requirement is well-known to be associated with lower islet cell yield after transplantation [25,37]. Low islet yields are common in patients with long-term chronic pancreatitis, as inflammation and fibrosis lead to pancreatic endocrine failure over time [38,39]. In the early stages of chronic pancreatitis, islet/ $\beta$-cell remains intact morphologically and functionally and patients usually do not have diabetes [17]. In contrast, the number of islet cells were shown to be significantly reduced corresponding to the stage of the disease before the onset of diabetes [7,9]. Both the exocrine and endocrine tissues have greater destruction in chronic pancreatitis patients compared to patients with minimal duct disease or nondilated chronic pancreatitis [40]. Thus, islet transplantation early in the progression of chronic pancreatitis can maximally preserve the endocrine function of the islets [37].

\section{APPROACHES THAT CAN IMPROVE THE FUNCTION OF ISLETS DURING TP-IAT}

Strategies that enable $\beta$ cell resistance to stresses during TP-IAT would prevent $\beta$ cell apoptosis, thereby improving clinical application of islet transplantation $[4,27,29]$. Several approaches are currently being explored to improve islet survival after transplantation including induction of protective genes expression ex vivo in islets during harvest, physically isolating islets from insults using encapsulation techniques, transplanting islets to a better site that promote survival, and so on (Figure 1).

Induction expression of protective gene has been shown able to protect islet cells from stress-induced apoptosis [41]. A protective gene is a gene that is upregulated in response to stress through specific signaling cascades and transcription factor regulation that when induced participate in promoting cell survival [41]. Many protective genes including heme oxygenase (HO-1), A20, B-cell lymphoma 2 (Bcl-2), Bcl-x, heat shock proteins, biliverdin reductase (BVR), and antioxidant enzymes have been found to be expressed in pancreatic islets, and their induction leads to protection against apoptosis and other injuries while their absence leads to a heightened response to stress [41-45]. Most protective genes exert their protection via their anti-inflammatory property and prevention of $\beta$ cell apoptosis.

Islet encapsulation with biocompatible materials have been shown function as an immunoisolation approach to facilitate survival of syngeneic, allogeneic and xenogeneic islets for decades [47-49]. Islet encapsulation can exert both "isolation" and "modulation" effects by physically isolating islets from complement molecules, IgG and host immune cells while delivering cytoprotective molecules locally to the islets to protect those islets from stress-induced apoptosis. Islets from chronic pancreatitis patients are extremely fragile due to long-term inflamemation in the pancreas. Therefore coating islets with nanoparticles loaded with protective molecules may well preserve their function after islet autotransplantation.

Significant progress has been made in developing suitable materials with reliable biocompatibility, mechanical and chemical stability, and required permselectivity for cell encapsulation [50-53]. Islet encapsulation with microcapsules prevents them from apoptosis [52,54]. Modifying islet surfaces with bioreactive chemicals prevents blood-mediated inflammatory responses [55] and prolonged survival of islet allograft [56]. Coating islets with FDA-approved poly(lactide-co-glycolide) (PLGA) nanoparticles increase islet function [57,58]. PLGA has been developed for many years and approved by the FDA for drug delivery based on its biodegradability, drug biocompatibility, suitable biodegradation kinetics and mechanical properties and ease of processing [59-61]. Loading drugs into nanoparticles where drugs are only active in the target area of the body, such as locally to islets, can avoid toxicity and side effects when administered systemically [62].

In addition, transplanting islets into other sites less stressful may promote their survival. Currently islets are transplanted into the liver of patient via portal vein infusion. However, the liver is not the ideal site for islet survival after transplantation due to the instant blood-mediated inflammatory reaction (IBMIR), hypoxia and inflammatory cytokine release by surrounding tissue induced by capillary bed occlusion in hepatic microvasculature $[63,64]$. In addition islets implanted in the liver are exposed to a non-native mechanical stress and exposure to toxins filtered through the liver that further impedes islet survival and function [65,66]. Other promising alternative sites currently being explored include subcutaneous, intramuscular, omental, and bone marrow sites [46,67-71].

In conclusion, current work has demonstrated apoptosis of $\beta$ cell in patients with chronic pancreatitis due to inflammation and inflammatory cytokines. These find- 
ings serve to explain the late onset of diabetes in patients with long-standing chronic pancreatitis. When islets in patients with chronic pancreatitis are autologously transplanted, additional islet stressors result in $\beta$ cell loss through apoptosis. Strategies that can prevent $\beta$ cell death during these processes can benefit patients with chronic pancreatitis and perhaps more importantly lead to new understanding of diabetes of all causes.

\section{ACKNOWLEDGEMENTS}

This study was supported in part by the South Carolina Clinical \& Translational Research (SCTR) Institute, with an academic home at the Medical University of South Carolina CTSA, NIH/NCRR Grant Number UL1RR029882 and the JDRF grant 5-2012-149 (to H.W. and D.A.).

\section{REFERENCES}

[1] Talukdar, R., Saikia, N., Singal, D.K. and Tandon, R. (2006) Chronic pancreatitis: Evolving paradigms. Pancreatology, 6, 440-449. doi:10.1159/000094561

[2] Dixon, E., Graham, J.S., Sutherland, F. and Mitchell, P.C. (2004) Splenic injury following endoscopic retrograde cholangiopancreatography: A case report and review of the literature. Journal of the Society of Laparoendoscopic Surgeons, 8, 275-277.

[3] Manciu, N., Beebe, D.S., Tran, P., Gruessner, R., Sutherland, D.E. and Belani, K.G. (1999) Total pancreatectomy with islet cell autotransplantation: Anesthetic implications. Journal of Clinical Anesthesia, 11, 576-582. doi:10.1016/S0952-8180(99)00100-2

[4] Dixon, J., DeLegge, M., Morgan, K.A. and Adams, D.B. (2008) Impact of total pancreatectomy with islet cell transplant on chronic pancreatitis management at a disease-based center. The American Surgeon, 74, 735-738.

[5] Wahoff, D.C., Papalois, B.E., Najarian, J.S., et al. (1995) Autologous islet transplantation to prevent diabetes after pancreatic resection. Annals of Surgery, 222, 562-575.

[6] Bhanot, U.K. and Moller, P. (2009) Mechanisms of parenchymal injury and signaling pathways in ectatic ducts of chronic pancreatitis: Implications for pancreatic carcinogenesis. Laboratory Investigation, 89, 489-497. doi:10.1038/labinvest.2009.19

[7] Schrader, H., et al. (2009) Reduced pancreatic volume and beta-cell area in patients with chronic pancreatitis. Gastroenterology, 136, 513-522. doi:10.1053/j.gastro.2008.10.083

[8] Mitchell, R.M., Byrne, M.F. and Baillie, J. (2003) Pancreatitis. Lancet, 361, 1447-1455. doi:10.1016/S0140-6736(03)13139-X

[9] Mitnala, S., Pondugala, P.K., et al. (2010) Reduced expression of PDX-1 is associated with decreased beta cell function in chronic pancreatitis. Pancreas, 39, 856-862. doi:10.1097/MPA.0b013e3181d6bc69

[10] Davalli, A.M., Scaglia, L., Zangen, D.H., et al. (1996) Vulnerability of islets in the immediate posttransplanta- tion period. Dynamic changes in structure and function, Diabetes, 45, 1161-1167. doi:10.2337/diabetes.45.9.1161

[11] Cui, Y. and Andersen, D.K. (2011) Pancreatogenic diabetes: Special considerations for management. Pancreatology: Official Journal of the International Association of Pancreatology, 11, 279-294. doi:10.1159/000329188

[12] Lankisch, P.G. (2001) Natural course of chronic pancreatitis. Pancreatology: Official Journal of the International Association of Pancreatology, 1, 3-14. doi:10.1159/000055786

[13] Bateman, A.C., Turner, S.M., et al. (2002) Apoptosis and proliferation of acinar and islet cells in chronic pancreatitis: Evidence for differential cell loss mediating preservation of islet function. Gut, 50, 542-548. doi:10.1136/gut.50.4.542

[14] Hasel, C., Rau, B., et al. (2001) Differential and mutually exclusive expression of CD95 and CD95 ligand in epithelia of normal pancreas and chronic pancreatitis. Journal of Technical Methods and Pathology, 81, 317-326.

[15] Hasel, C., Durr, S., et al. (2003) In chronic pancreatitis, widespread emergence of TRAIL receptors in epithelia coincides with neoexpression of TRAIL by pancreatic stellate cells of early fibrotic areas. Journal of Technical Methods and Pathology, 83, 825-836.

[16] Lamhamedi-Cherradi, S.E., Zheng, S., Tisch, R.M. and Chen, Y.H. (2003) Critical roles of tumor necrosis factor-related apoptosis-inducing ligand in type 1 diabetes. Diabetes, 52, 2274-2278. doi:10.2337/diabetes.52.9.2274

[17] Bhanot, U.K. and Moller, P. (2009) Mechanisms of parenchymal injury and signaling pathways in ectatic ducts of chronic pancreatitis: Implications for pancreatic carcinogenesis. Journal of Technical Methods and Patho$\log y, \mathbf{8 9}, 489-497$.

[18] Degli-Esposti, M.A., Dougall, W.C., et al. (1997) The novel receptor TRAIL-R4 induces NF-kappaB and protects against TRAIL-mediated apoptosis, yet retains an incomplete death domain. Immunity, 7, 813-820. doi:10.1016/S1074-7613(00)80399-4

[19] Chen, X., Ji, B., Han, B., Ernst, S.A., Simeone, D. and Logsdon, C.D. (2002) NF-kappaB activation in pancreas induces pancreatic and systemic inflammatory response. Gastroenterology, 122, 448-457. doi:10.1053/gast.2002.31060

[20] Butler, A.E., Janson, J., et al. (2003) Beta-cell deficit and increased beta-cell apoptosis in humans with type 2 diabetes. Diabetes, 52, 102-110. doi:10.2337/diabetes.52.1.102

[21] Donath, M.Y., Storling, J., et al. (2008) Cytokines and beta-cell biology: From concept to clinical translation. Endocrine Reviews, 29, 334-350. doi:10.1210/er.2007-0033

[22] Tandon, R.K. and Garg, P.K. (2011) Oxidative stress in chronic pancreatitis: Pathophysiological relevance and management. Antioxidants \& Redox Signaling, 15, 27572766. doi:10.1089/ars.2011.4115

[23] Pavan Kumar, P., Radhika, G., et al. (2012) Interferon 
gamma and glycemic status in diabetes associated with chronic pancreatitis. Pancreatology, 12, 65-70.

[24] Mitnala, S., Pondugala, P.K., et al. (2010) Reduced expression of PDX-1 is associated with decreased beta cell function in chronic pancreatitis. Pancreas, 39, 856-862. doi:10.1097/MPA.0b013e3181d6bc69

[25] Blondet, J.J., Carlson, A.M., et al. (2007) The role of total pancreatectomy and islet autotransplantation for chronic pancreatitis. The Surgical clinics of North America, 87, 1477-1501. doi:10.1016/j.suc.2007.08.014

[26] Argo, J.L., Contreras, J.L., Wesley, M.M. and Christein, J.D. (2008) Pancreatic resection with islet cell autotransplant for the treatment of severe chronic pancreatitis. The American Surgeon, 74, 530-536.

[27] Nath, D.S., Kellogg, T.A. and Sutherland, D.E. (2004) Total pancreatectomy with intraportal auto-islet transplantation using a temporarily exteriorized omental vein. Journal of the American College of Surgeons, 199, 994995. doi:10.1016/j.jamcollsurg.2004.07.033

[28] Bellin, M.D. and Sutherland, D.E. (2010) Pediatric islet autotransplantation: Indication, technique, and outcome. Current Diabetes Reports, 10, 326-331. doi:10.1007/s11892-010-0140-4

[29] Kobayashi, T., Manivel, J.C., et al. (2011) Correlation of histopathology, islet yield, and islet graft function after islet autotransplantation in chronic pancreatitis. Pancreas, 40, 193-199. doi:10.1097/MPA.0b013e3181fa4916

[30] Farney, A.C., Najarian, J.S., et al. (1991) Autotransplantation of dispersed pancreatic islet tissue combined with total or near-total pancreatectomy for treatment of chronic pancreatitis. Surgery, 110, 427-437.

[31] Robertson, R.P., Lanz, K.J., et al. (2001) Prevention of diabetes for up to 13 years by autoislet transplantation after pancreatectomy for chronic pancreatitis. Diabetes, 50, 47-50. doi:10.2337/diabetes.50.1.47

[32] Biarnes, M., Montolio, M., et al. (2002) Beta-cell death and mass in syngeneically transplanted islets exposed to short- and long-term hyperglycemia. Diabetes, 51, 66-72. doi:10.2337/diabetes.51.1.66

[33] Ahn, Y.B., Xu, G., et al. (2007) Changes in gene expression in beta cells after islet isolation and transplantation using laser-capture microdissection. Diabetologia, 50, 334-342.

doi:10.1007/s00125-006-0536-5

[34] Davalli, A.M., Scaglia, L., et al. (1995) Early changes in syngeneic islet grafts: effect of recipient's metabolic control on graft outcome. Transplantation Proceedings, 27, 3238-3239.

[35] Bhardwaj, P., Thareja, S., et al. (2004) Micronutrient antioxidant intake in patients with chronic pancreatitis, Tropical gastroenterology. Journal of the Digestive Diseases Foundation, 25, 69-72.

[36] Hsu, J.T., Yeh, C.N., et al. (2005) Outcome of pancreaticoduodenectomy for chronic pancreatitis. Journal of the Formosan Medical Association, 104, 811-815.

[37] Ong, S.L., Gravante, G., et al. (2009) Total pancreatectomy with islet autotransplantation: an overview. Journal of the International Hepato Pancreato Biliary Associa- tion, 11, 613-621.

doi:10.1111/j.1477-2574.2009.00113.x

[38] Howes, N., Lerch, M.M., et al. (2004) Clinical and genetic characteristics of hereditary pancreatitis in Europe. Clinical Gastroenterology and Hepatology, 2, 252-261. doi:10.1016/S1542-3565(04)00013-8

[39] Ammann, R.W. (2006) Diagnosis and management of chronic pancreatitis: Current knowledge. Swiss Medical Weekly, 136, 166-174.

[40] De Cock, H.E., Forman, M.A., et al. (2007) Prevalence and histopathologic characteristics of pancreatitis in cats. Veterinary Pathology, 44, 39-49. doi:10.1354/vp.44-1-39

[41] Wang, H., Ferran, C., et al. (2011) Induction of protective genes leads to islet survival and function. Journal of Transplantation, 2011, 141898. doi:10.1155/2011/141898

[42] Wang, H., Wu, H., et al. (2012) Activation of peroxisome proliferator-activated receptor gamma prolongs islet allograft survival, cell transplantation. Cell Transplant, 21, 2111-2118.

[43] Emamaullee, J.A. and Shapiro, A.M. (2006) Interventional strategies to prevent beta-cell apoptosis in islet transplantation. Diabetes, 55, 1907-1914. doi:10.2337/db05-1254

[44] Grey, S.T., Arvelo, M.B., et al. (1999) A20 inhibits cytokine-induced apoptosis and nuclear factor kappaB-dependent gene activation in islets. The Journal of Experimental Medicine, 190, 1135-1146.

doi:10.1084/jem.190.8.1135

[45] Riachy, R., Vandewalle, B., et al. (2002) 1,2,5-dihydroxyvitamin D3 protects RINm5F and human islet cells against cytokine-induced apoptosis: Implication of the antiapoptotic protein A20. Endocrinology, 143, 48094819. doi:10.1210/en.2002-220449

[46] Christoffersson, G., Carlsson, P.O. and Phillipson, M. (2011) Intramuscular islet transplantation promotes restored islet vascularity. Islets, 3, 69-71. doi:10.4161/isl.3.2.14997

[47] Basta, G. and Calafiore, R. (2011) Immunoisolation of pancreatic islet grafts with no recipient's immunosuppression: Actual and future perspectives. Current Diabetes Reports, 11, 384-391. doi:10.1007/s11892-011-0219-6

[48] Fort, A., Fort, N., et al. (2008) Biohybrid devices and encapsulation technologies for engineering a bioartificial pancreas. Cell Transplantation, 17, 997-1003. doi:10.3727/096368908786991498

[49] Giraldo, J.A., Weaver, J.D. and Stabler, C.L. (2010) Tissue engineering approaches to enhancing clinical islet transplantation through tissue engineering strategies. Journal of Diabetes Science and Technology, 4, 12381247.

[50] Trivedi, N., Keegan, M., et al. (2001) Islets in alginate macrobeads reverse diabetes despite minimal acute insulin secretory responses. Transplantation, 71, 203-211. doi:10.1097/00007890-200101270-00006

[51] van Schilfgaarde, R. and de Vos, P. (1999) Factors influ- 
encing the properties and performance of microcapsules for immunoprotection of pancreatic islets. Journal of Molecular Medicine, 77, 199-205. doi:10.1007/s001090050336

[52] Sandberg, J.O., Olsson, N., et al. (1995) Immunosuppression, macroencapsulation and ultraviolet-B irradiation as immunoprotection in porcine pancreatic islet xenotransplantation. Pharmacology \& Toxicology, 76, 400-405. doi:10.1111/j.1600-0773.1995.tb00169.x

[53] Pollok, J.M., Ibarra, C., et al. (1998) Immuno-isolation of xenogenic islands of Langerhans in a tissue engineered autologous cartilage capsule. Zentralblatt fur Chirurgie, 123, 830-833.

[54] Qi, M., Gu, Y., et al. (2004) PVA hydrogel sheet macroencapsulation for the bioartificial pancreas. Biomaterials, 25, 5885-5892. doi:10.1016/j.biomaterials.2004.01.050

[55] Teramura, Y. and Iwata, H. (2008) Islets surface modification prevents blood-mediated inflammatory responses. Bioconjugate Chemistry, 19, 1389-1395. doi:10.1021/bc800064t

[56] Lee, D.Y., Park, S.J., et al. (2007) Highly poly(ethylene) glycolylated islets improve long-term islet allograft survival without immunosuppressive medication. Tissue Engineering, 13, 2133-2141. doi:10.1089/ten.2006.0009

[57] Basarkar, A. and Singh, J. Poly (2009) (lactide-co-glycolide)-polymethacrylate nanoparticles for intramuscular delivery of plasmid encoding interleukin-10 to prevent autoimmune diabetes in mice. Pharmaceutical Research, 26, 72-81.

[58] Mao, G.H., Chen, G.A., et al. (2009) The reversal of hyperglycaemia in diabetic mice using PLGA scaffolds seeded with islet-like cells derived from human embryonic stem cells. Biomaterials, 30, 1706-1714. doi:10.1016/j.biomaterials.2008.12.030

[59] Jain, R., Shah, N.H., et al. (1998) Controlled drug delivery by biodegradable poly(ester) devices: Different preparative approaches. Drug Development and Industrial Pharmacy, 24, 703-727. doi:10.3109/03639049809082719

[60] Jain, R.A. (2000) The manufacturing techniques of various drug loaded biodegradable poly(lactide-co-glycolide) (PLGA) devices. Biomaterials, 21, 2475-2490. doi:10.1016/S0142-9612(00)00115-0

[61] Lu, J.M., Wang, X., et al. (2009) Current advances in research and clinical applications of PLGA-based nano- technology. Expert Review of Molecular Diagnostics, 9, 325-341. doi:10.1586/erm.09.15

[62] Athanasiou, K.A., Niederauer, G.G. and Agrawal, C.M. (1996) Sterilization, toxicity, biocompatibility and clinical applications of polylactic acid/polyglycolic acid copolymers. Biomaterials, 17, 93-102. doi:10.1016/0142-9612(96)85754-1

[63] Yin, D., Ding, J.W., et al. (2006) Liver ischemia contributes to early islet failure following intraportal transplanttation: Benefits of liver ischemic-preconditioning. American Journal of Transplantation, 6, 60-68. doi:10.1111/j.1600-6143.2005.01157.x

[64] Wilson, J.T. and Chaikof, E.L. (2008) Thrombosis and inflammation in intraportal islet transplantation: A review of pathophysiology and emerging therapeutics. Journal of Diabetes Science and Technology, 2, 746-759. doi:10.1097/01.tp.0000290388.70019.6e

[65] Cardani, R., Pileggi, A., et al. (2007) Allosensitization of islet allograft recipients. Transplantation, 84, 1413-1427.

[66] Rickels, M.R., Kamoun, M., et al. (2007) Evidence for allograft rejection in an islet transplant recipient and effect on beta-cell secretory capacity. The Journal of Clinical Endocrinology and Metabolism, 92, 2410-2414. doi:10.1210/jc.2007-0172

[67] Lund, T., Korsgren, O., et al. (2010) Sustained reversal of diabetes following islet transplantation to striated musculature in the rat. The Journal of Surgical Research, 160, 145-154. doi:10.1016/j.jss.2008.11.009

[68] Salazar-Banuelos, A., Wright, J.R., et al. (2008) Pancreatic islet transplantation into the bone marrow of the rat. American Journal of Surgery, 195, 674-678. doi:10.1016/j.amjsurg.2007.12.040

[69] Berman, D.M., O’Neil, J.J., et al. (2009) Long-term survival of nonhuman primate islets implanted in an omental pouch on a biodegradable scaffold. American Journal of Transplantation, 9, 91-104. doi:10.1111/j.1600-6143.2008.02489.x

[70] van der Windt, D.J., Echeverri, G.J., et al. (2008) The choice of anatomical site for islet transplantation. Cell Transplantation, 17, 1005-1014. doi:10.3727/096368908786991515

[71] Pileggi, A., Molano, R.D., et al. (2006) Reversal of diabetes by pancreatic islet transplantation into a subcutaneous, neovascularized device. Transplantation, 81, 13181324. doi:10.1097/01.tp.0000203858.41105.88 